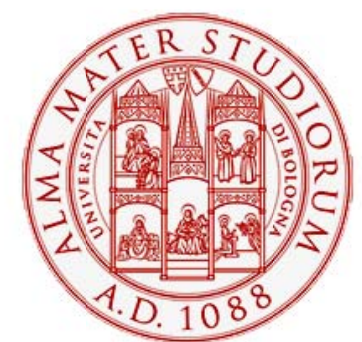

Alma Mater Studiorum - Università di Bologna DEPARTMENT OF ECONOMICS

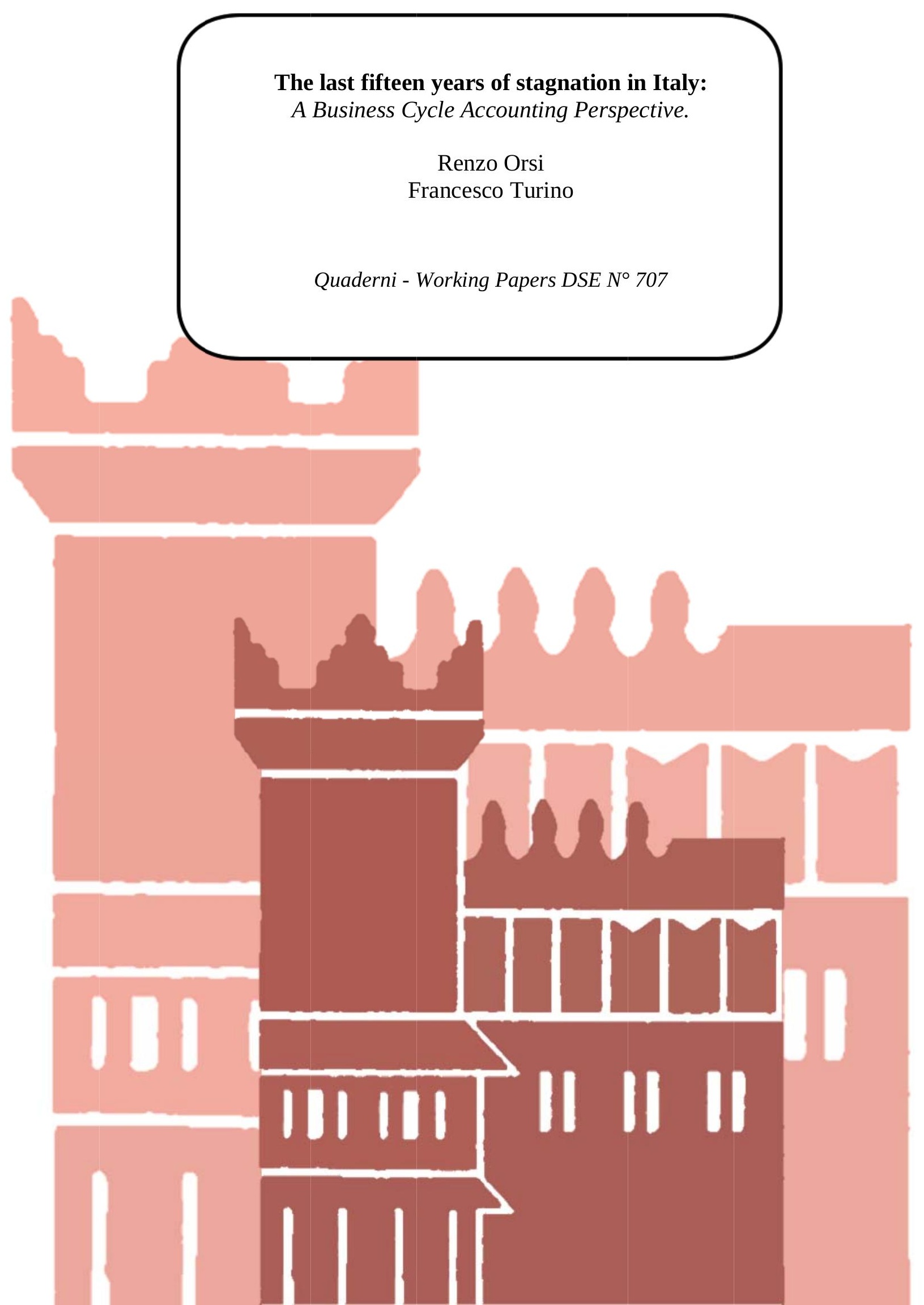




\title{
The last fifteen years of stagnation in Italy: A Business Cycle Accounting Perspective.
}

\author{
Renzo Orsi* \\ Universitá di Bologna
}

\author{
Francesco Turino ${ }^{\dagger}$ \\ Universitat D'Alacant \\ Universitá di Bologna
}

June 16, 2010

\begin{abstract}
In this paper, we investigate possible sources of declining economic growth performance in Italy starting around the middle of the '90s. A long-run data analysis suggests that the poor performance of the Italian economy cannot be ascribed to an unfortunate business cycle contingency. The rest of the euro area countries have shown better performance, and the macroeconomic data show that the Italian economy has not grown as rapidly as these other European economies. We investigate the sources of economic fluctuations in Italy by applying the Business Cycle Accounting procedure introduced by Chari, Kehoe and McGrattan (2007). We analyze the relative importance of efficiency, labor, investment and government wedges for business cycles in Italy over the 1982-2008 period. We find that different wedges have played different roles during the period, but the efficiency wedge is revealed to be the main factor responsible for the stagnation phase beginning around 1995. Our findings also show that the improvement in labor market distortions that occurred in Italy during the '90s provided an alleviating effect, preventing an even stronger slowdown in per capita output growth.
\end{abstract}

JEL Classification: E65, O41, O52

Keywords: Business Cycle Accounting, Macro Model, Efficiency Wedge, Growth Model, Italy, Stagnation

\footnotetext{
*Department of Economics, University of Bologna. Contact email: renzo.orsi@unibo.it

${ }^{\dagger}$ Department of Economics, University of Bologna. Contact email: fturino@merlin.fae.ua.es
} 


\section{Introduction}

In the last 15 years, the Italian economy has experienced a protracted slowdown in per capita output growth. A long-run data analysis suggests that this poor performance of the Italian economy cannot be ascribed to an unfortunate business cycle contingency. The rest of the euro area countries have, in fact, shown better performance, and the macroeconomic data show (the OECD and ISTAT, among others) that the Italian economy has not grown as fast as these other European economies. There is a firm belief among a large number of political economy analysts that this weak performance must be ascribed to structural features of the Italian production system, which have largely remained unchanged over decades and have turned out to be unsuitable for facing the competitive pressure on international markets or for taking advantage of the opportunities offered by technological innovations and European economic integration. The existing literature has also offered different explanations for the poor performance of the Italian economy, including the slowdown in labor productivity and TFP growth (Daveri and Jona-Lasinio, 2005), labor market reforms (Boeri and Garibaldi, 2007) and the lack of investment in innovation and R\&D activity (ISTAT and the OECD). It is of particular interest to understand why this decline occurred because competing explanations have different implications in terms of macroeconomic policy. Thus, a thorough analysis of this growth deficit and the productivity slowdown is appropriate and desirable, especially one that works toward identifying specific causes of the Italian economic slowdown or stagnation. This question appears particularly important given that Italy is among the most important economies in the European Union.

This paper contributes to the existing literature by studying the stagnation phase of the Italian economy from a general equilibrium perspective, making use of the business cycle accounting (BCA) procedure proposed by Chari, Kehoe and McGrattan (2007) (hereafter CKM). This procedure is particularly suitable for our purposes because it decomposes movements in macroeconomic aggregates into different contributing factors, thereby providing a useful tool for understanding which distortions are mainly responsible for specific cyclical episodes. More specifically, CKM show that a large class of dynamic stochastic general equilibrium (DSGE) models with frictions and shocks is observationally equivalent to a prototype real business cycle (RBC) model with four correlated wedges. For instance, an economy with sticky wages and monetary shocks is equivalent to the prototype RBC model with a labor wedge. In a similar way, an economy in which the technological innovation is constant and input frictions vary over time is equivalent to the prototype model with an efficiency wedge. ${ }^{1}$ These wedges, which, by construction, are related to the structure of the unknown data generating process, can be computed by using the prototype model with actual data. This computation allows us quantify the relative importance of different factors in accounting for the stagnation phase of the Italian economy. Most importantly, because of the equivalence results, to discriminate among competing mechanisms in the business cycle.

We apply the BCA procedure by using quarterly data for the Italian economy over the period from 1982-2008. Relative to the stagnation phase, which starts around the middle of the '90s, we focus on a longer period to capture an apparent change of regime experienced by the Italian economy. In fact, the aggregate data show that from 1982 to 2008, the Italian

\footnotetext{
${ }^{1}$ Other equivalence results are reported in CKM (2007).
} 
economy switched from a protracted period of growth without an increase in employment (jobless growth regime), which occurred from the early '80s to the middle of the '90s, to a phase of growthless job creation in the subsequent 15 years, where the Italian economy experienced a significant slowdown in output growth associated with a substantial increase in total employment. Comparing the two different contexts provides us with additional information for a better understanding of the main driving forces behind the stagnation phase of the Italian economy.

To preview our results, we find that the efficiency wedge plays a prominent role in accounting for Italian output fluctuations. Relative to the jobless growth regime, the slowdown in the per capita output growth that occurred during the stagnation phase is mainly driven by a strong worsening of the distortions that manifest themselves as the efficiency wedge. This finding is consistent with the results provided by Daveri and Jona-Lasinio (2005), which suggest that the Italian economic decline is mainly due to a deceleration in the TFP growth. Our analysis, however, provides additional insights, showing that the sizeable increase in the labor factor that occurred during the stagnation phase can be largely explained by an attenuation of labor market distortions captured by the labor wedge. The prototype model with the efficiency wedge alone fails to account for the observed labor dynamics during this period. Additionally, we find that such improvements in labor market distortions have also provided an alleviating effect, preventing an even stronger slowdown in the per capita output growth. We identify which distortions the labor wedge captures, finding a prominent role for the labor market reforms in Italy. Since 1987, Italy has experienced a sequence of labor market reforms, the most important of which occurred in 1997 (the so-called Treu

Law). Such reforms where mainly designed to increase the flexibility of the labor factor, making the utilization of non-permanent contracts more loosely regulated. We find in our analysis that the improvements in the labor wedge beginning in the middle of the '90s can be interpreted as evidence supporting the hypothesis that such reforms succeeded in reducing labor market distortions.

The paper is organized as follows. In section 2, we report some stylized facts about the Italian economy, while in section 3 we specify the prototype model that we used in the business cycle accounting procedure. In section 4 we obtain wedges from Italian data, while in section 5, we compare the data with the model's predictions for the different types of wedges. In section 6 , we provide specific comments regarding the labor wedge in relation to the labor market reforms initiated in Italy during the '90s, and some concluding remarks are provided in section 7 .

\section{Stylized Facts}

In this section, we outline some important regularities in macroeconomic data that provide an insightful portrait of the weak performance of the Italian economy during the last 15 years. The presence of Italy's economic decline is supported by different pieces of evidence, some of which have been reported below to form an idea of the actual context. The left panel of figure 1 graphs Italy's growth rate of per capita output from 1950 to 2009. As shown by the figure, the per capita growth rate in Italy has constantly declined since the '50s, moving from a yearly average growth rate of $5.47 \%$ in the '50s to an average 

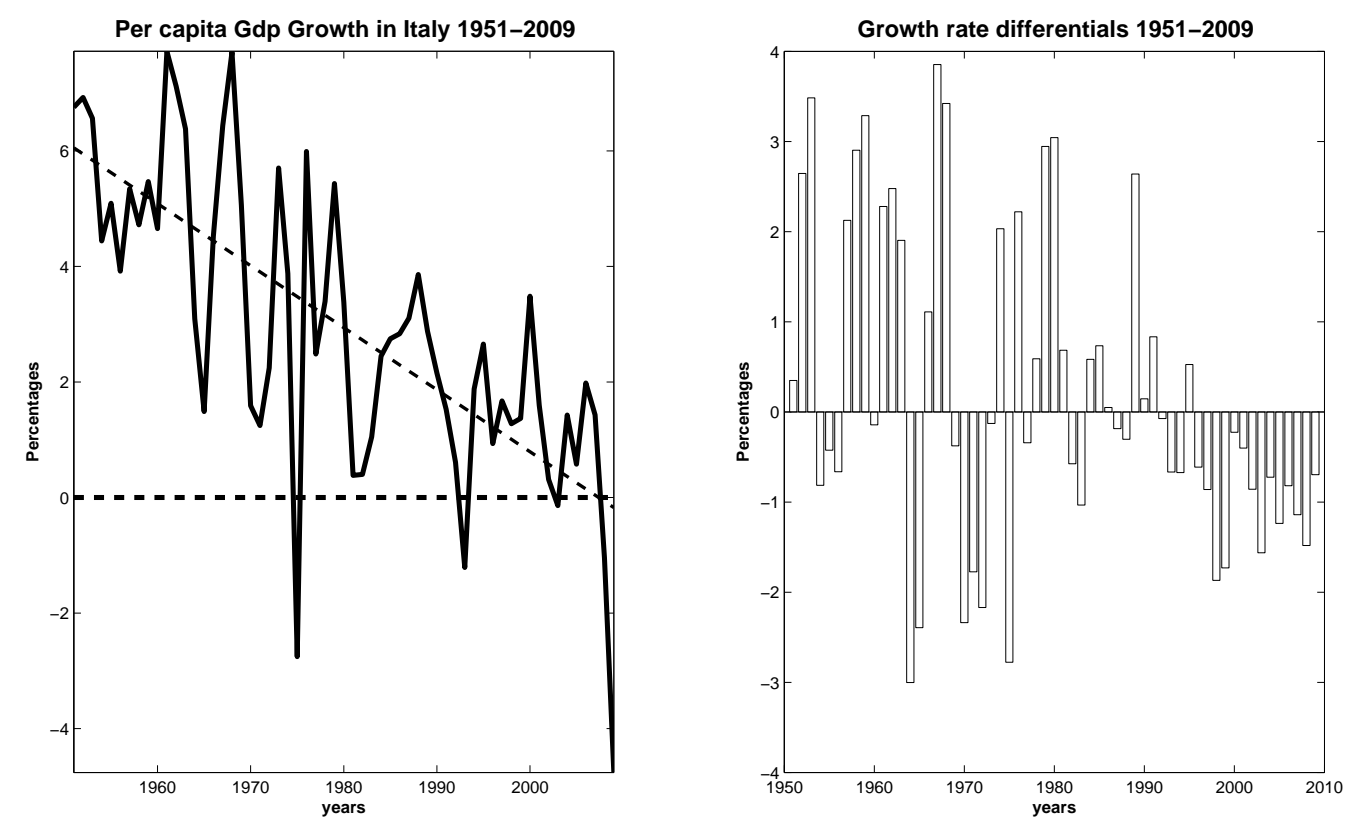

Figure 1: The Italian economic stagnation. Panel 1 graphes the per capita GDP growth rate. Panel 2 graphes the growth rate differentials between Italy and the average across Spain, France, Germany and the UK. Yearly data from The Conference Board Total Economy Database

growth rate of $0.49 \%$ in the 2000s. ${ }^{2}$ This feature, however, can be partly explained by the convergence theory based upon standard neoclassical growth models, which have recently been advocated for Europe as a whole (Blanchard, 2004); this theory states that a mature economy, in the long run, tends to converge to a steady-state equilibrium without necessarily entailing a loss in the standard of living.

A clearer picture of the poor performance of the Italian economy emerges by comparing Italy with other European countries. The right panel of figure 1 draws such a comparison by plotting the growth rate differential between Italy and the average growth among other European countries - namely, Germany, France, the UK and Spain - whose economic intensity is comparable with that of Italy. The figure clearly shows that, unlike the previous period, starting around 1995, Italy's per capita GDP has systematically grown at a decreased rate relative to other large countries in Europe have. This trend suggests that the slowdown that occurred in Italy since 1995 is not only related to an unfortunate business cycle context but also, and more likely, to unique characteristics of the Italian economy.

Aggregate data for the last 15 years, however, show that the decline in per capita GDP growth is not related to a decrease in labor input, which, on the contrary, displayed a considerable improvement. This improvement is documented in the first two rows of table 2, which display the average yearly growth of both per capita GDP (first row) and total

\footnotetext{
${ }^{2}$ Excluding the 2009 crisis, from 2000 to 2008, the average growth rate in Italy was equal to $1 \%$ each year.
} 
Table 1: GDP, Employment and Labor Productivity, 1980-2007

\begin{tabular}{lccccc}
\hline \hline Variable & $1980-2007$ & $1980-1995$ & $1995-2007$ & $2000-2003$ & $2003-2007$ \\
\hline \hline GPD growth & 1.7 & 1.9 & 1.3 & 1.3 & 1.3 \\
Employment Growth & 0.4 & -0.2 & 1.2 & 1.5 & 1.2 \\
\hline \hline Labor Productivity Growth & 1.4 & 2.2 & 0.4 & -0.8 & 0.4 \\
Contribution from: & & & & & \\
Capital per Hours Worked & 0.7 & 1.0 & 0.4 & 0.5 & 0.1 \\
ICT & 0.2 & 0.2 & 0.0 & 0.0 & -0.1 \\
No ICT & 0.6 & 0.8 & 0.3 & 0.5 & 0.2 \\
TFP & 0.7 & 1.2 & 0.0 & -1.3 & 0.3 \\
\hline \hline
\end{tabular}

employment (second row) in different sub-periods. Comparing the 1980-1995 period with the 1995-2007 period, we note that while the per capita GDP growth slowdown, ${ }^{3}$ the Italian employment instead substantially increased, moving from a negative $(-0.2 \%)$ to a positive $(1.2 \%)$ growth rate. This feature of the data captures an apparent change of regime, where Italy moved from a phase of jobless growth to a phase of growthless job creation (Boeri and Garibaldi, 2007).

Many authors, such as Daveri and Jona-Lasinio (2005), have suggested that the weak performance of the Italian economy (in terms of per capita GDP growth) can essentially be related to a significant slowdown in labor productivity that is mainly due to a decline in TPF growth. This feature is documented in the second panel of table 1, which displays the average yearly growth of labor productivity. As shown by the table, the dynamic evolution of labor productivity shows a robust growth equal to 2.2 percentage points in the period between 1980-1995, followed by a serious slowdown, which reduces the growth rate to 0.4 percentage points over the period 1995-2007. Analyzing the factors contributing to the labor productivity dynamics, the main point of difference between the two sub-periods is that in the first-period, labor productivity growth is due to the combined contribution of TFP with capital per worked hour; however, in the second sub-period, 1995-2007, labor productivity growth has mainly been drawn by the capital accumulation per worked hours, as the TFP provides a contribution practically equal to zero. In addition, since 2000, an increasing capital intensity has been revealed as the only source of labor productivity, partially compensating, for the negative effect resulting from the TFP reduction. ${ }^{4}$ Moreover, the contribution imputable to the capital per worked hours to labor productivity growth is mainly related to the increase in the no-ICT capital stock, as the contribution of the ICT component is essentially zero.

To come to the point, our findings highlight the following stylized facts:

\footnotetext{
${ }^{3}$ Moving from an average growth of $1.9 \%$ to an average growth of $1.3 \%$

${ }^{4} \mathrm{An}$ important difference between manufacturing and services can be noted: the manufacturing sector shows a deceleration path since the middle of the '90s, while in services, TFP softly accelerated after 1995, even if it has turned negative in recent years.
} 
- In the last 60 years, the yearly growth rate of Italy's per capita GDP has constantly declined;

- From 1995 to 2009, Italy has systematically grown less than other large European countries;

- Since 1995, employment growth has significantly increased, while labor productivity growth and TFP growth have shown a dramatic slowdown.

\section{The prototype model}

In this section, we lay out the prototype business cycle model that we use for the accounting exercise. We assume that the economy is characterized by consumers and firms interacting in an environment with perfectly competitive markets. The model is characterized by four exogenous stochastic variables that distort the agents' decisions: the efficiency wedge, $A_{t}$, the labor wedge, $\left(1-\tau_{l, t}\right)$, the investment wedge, $1 /\left(1+\tau_{x, t}\right)$, and the government wedge, $g_{t}$. As in CKM (2007), we assume that these wedges are functions of an underlying random variable, $s^{t}$, which describes the history of events from an initial date 0 to the current period $t$.

In this model, the representative household chooses per capita consumption $\left(c_{t}\right)$ and per capita labor $\left(l_{t}\right)$ to maximize the expected utility function given by

$$
E_{0} \sum_{t=0}^{\infty} \beta^{t} U\left(c_{t}, l_{t}\right) N_{t}
$$

subject to the budget constraint

$$
c_{t}+\left(1+\tau_{x, t}\right) x_{t}=\left(1-\tau_{l, t}\right) w_{t} l_{t}+r_{t} k_{t}+T_{t}
$$

and the law of motion for capital

$$
\left(1+\gamma_{n}\right) k_{t+1}=(1-\delta) k_{t}+x_{t}
$$

where $k_{t}$ denotes the per capita capital stock, $w_{t}$ is the wage rate, $r_{t}$ is the rental rate of capital, $x_{t}$ is investment, $\beta \in(0,1)$ is the subjective discount factor, $T_{t}$ is per capita lump sum transfers, $\delta \in(0,1)$ is the depreciation rate of capital, and $N_{t}$ is the population with a constant growth rate equal to $\left(1+\gamma_{n}\right)$. The labor wedge, $\left(1-\tau_{l, t}\right)$, and the investment wedge, $1 /\left(1+\tau_{x, t}\right)$, are introduced into the model through the budget constraint (2) in a way that resembles taxes on, respectively, labor income and investment.

On the firm's side, the profit maximization problem is given by

$$
\max _{k_{t}, l_{t}} A_{t} F\left(k_{t},(1+\gamma)^{t} l_{t}\right)-w_{t} l_{t}-r_{t} k_{t}
$$

where $(1+\gamma)$ is the rate of labor-augmenting technological progress which is assumed to be constant over time, while $A_{t}$ is the efficiency wedge, resembling purely transitory variations in total factor productivity (TFP). 
The equilibrium of the model economy is thus described by the following system of equations:

$$
\begin{gathered}
-\frac{U_{l, t}}{U_{c t}}=\left(1-\tau_{l, t}\right) A_{t} F_{l, t} \\
U_{c, t}\left(1+\tau_{x, t}\right)=\beta E_{t}\left\{U_{c, t+1}\left[(1-\delta)\left(1+\tau_{x, t+1}\right)+A_{t+1} F_{k, t+1}\right]\right\} \\
\left(1+\gamma_{n}\right)(1+\gamma) k_{t+1}=(1-\delta) k_{t}+x_{t} \\
c_{t}+i_{t}+g_{t}=y_{t} \\
y_{t}=A_{t} F\left(k_{t},(1+\gamma)^{t} l_{t}\right)
\end{gathered}
$$

where $g_{t}$ denotes the government expenditures wedge and $U_{i, t}$ and $F_{s, t}$ respectively denote the derivatives of the utility function and the production function with respect to the arguments $i$ and $s$ at date $t$.

\section{Measuring the Wedges}

The first step of the business cycle accounting procedure requires recovering wedges from the data. We apply this procedure to the Italian economy by making use of quarterly data from 1982 to $2008 .{ }^{5}$ To measure the various wedges, we first need to specify functional forms for preferences and production and assign values to the model's structural parameters. We assume that goods are produced via a Cobb-Douglass production function with laboraugmenting technical change of the form

$$
y_{t}=A_{t} k_{t}^{\alpha}\left((1+\gamma)^{t} l_{t}\right)^{1-\alpha}
$$

where $\alpha \in(0,1)$, while the instantaneous utility function is assumed to be separable in consumption and leisure as

$$
U\left(c_{t}, l_{t}\right)=\log \left(c_{t}\right)+\psi \log \left(1-l_{t}\right)
$$

where $\psi>0$ is a preference parameter controlling for the Frisch elasticity of labor supply. Our specification of preferences and technology are the same as those employed by CKM (2007) in their study of the US business cycle and also by Kersting (2008) in his study on the 1980s recession in the UK. The vector of the model's structural parameters, defined as $\Xi=\left[\beta, \alpha, \gamma, \gamma_{n}, \delta, \psi\right]$ is then calibrated as follows. The parameter values for $\alpha, \gamma, \gamma_{n}$ and $\psi$ are chosen such that the steady state of the model matches the specific characteristics of the Italian economy for the 1982-2008 period. More specifically, the intensity of labor in the production function, $\alpha$, is set to 0.42 so that in our model, the stationary labor income

\footnotetext{
${ }^{5}$ Details on the sources of data and transformations used in our analyses are both provided in the Appendix.
} 
share, $(1-\alpha)$, is $0.58 .{ }^{6}$ The rates of growth of technological progress, $\gamma$ and population, $\gamma_{n}$, are chosen such that, on a yearly basis, the population growth rate is $0.4 \%$, and GDP growth is $1.5 \% .^{7}$ The preference parameter, $\psi$, is set to 2.4 so that, conditional on all the other parameters, in the stationary equilibrium of the model, individuals devote $20 \%$ of their time to working activities. ${ }^{8}$ Finally, following CKM (2007), the rate of capital depreciation, $\delta$, and the subjective discount factor are chosen so that, on an annual basis, depreciation is $4.64 \%$, while the rate of time preferences is $3 \%$. These values are typically used in the business cycle literature.

Once functional forms are specified and structural parameters are calibrated, most of the wedges can be directly recovered by using actual data with the static equilibrium conditions (3), (6) and (7). More precisely, we first construct a sequence for the capital stock by using data on per capita investment, $x_{t}$, with the law of motion (5). Given data for output, $y_{t}$, capital stock, $k_{t}$ and labor input, $l_{t}$, we use equation (7) to measure the efficiency wedge, $A_{t}$. The government wedge, $g_{t}$, is instead taken directly from the data by using actual figures for the (model-consistent) government consumption expenditures. ${ }^{9}$ Hence, given data for investment and government wedge, we recover a sequence for consumption, $c_{t}$, by using the resources constraint (6), and, therefore, by making use of actual data for per capita hours worked, $l_{t}$, we compute the labor wedge, $\left(1+\tau_{l, t}\right)$, from the intra-temporal condition (3).

However, recovering the investment wedge, $\left[1 /\left(1+\tau_{x, t}\right)\right]$, is more complicated. Because the Euler equation (4) involves expectations, the decision rules for consumption and the other endogenous variables in the model implicitly depend upon the stochastic process driving the wedges. As such, following CKM (2007), we make use of the Markovian implementation by assuming that the vector $s_{t}=\left(\log \left(A_{t}\right), \tau_{l, t}, \tau_{x, t}, \log \left(g_{t}\right)\right)$ follows a $\operatorname{VAR}(1)$ process of the form

$$
s_{t+1}=[I-P] P_{0}+P s_{t}+\xi_{t+1}
$$

where $P_{0}$ is the vector of unconditional means for $S_{t}$ and $P$ is a matrix of coefficients, while $\xi_{t+1}$ is a normal i.i.d process with mean zero and covariance matrix $V$. This process is then used with the equilibrium conditions (3)-(7) in order to estimate the matrices $P_{0}, P$ and $V$ with a standard maximum likelihood procedure, as it is described, for instance, in Canova (2007). ${ }^{10}$ In short, once we have assigned values to all structural parameters, the model is first solved by log-linearizing the equilibrium conditions around the non-stochastic steady-state. This approach allows us to represent the rational expectation equilibrium the model economy through the following state-space form

$$
\begin{aligned}
X_{t+1} & =\Gamma_{1} X_{t}+\Psi \varepsilon_{t} \\
Y_{t} & =D X_{t}
\end{aligned}
$$

\footnotetext{
${ }^{6}$ Following Arpaia, Perz and Pichelmann (2009), figures for the labor income share are obtained using inter-sectoral data taken from the EU KLEMS database. The value 0.58 corresponds to the average labor share over the period between 1982-2008.

${ }^{7}$ Population refers to all individuals aged $15-64$ years.

${ }^{8}$ This value is equal to the average hours worked in a quarter as a fraction of the total quarterly hours for the period 1982-2008.

${ }^{9}$ Alternatively, we can recover the government wedge as a residual from the resources constraint (6) by using data for per capita consumption, $c_{t}$, per capita investment, $x_{t}$ and per capita output, $y_{t}$.

${ }^{10}$ In the computation, we define $\xi_{t+1}=Q \varepsilon_{t+1}$, where $Q$ is a lower triangular matrix and $\varepsilon_{t+1}$ is a white noise. This guarantees that the estimated matrix $V=Q Q^{\prime}$ is positive semi-definite.
} 
where $X_{t}=\left(\log \left(k_{t}\right), \log \left(A_{t}\right), \tau_{l, t}, \tau_{x, t}, \log \left(g_{t}\right), 1\right)^{\prime}$ denotes the vector of endogenous and exogenous state variables, while $Y_{t}=\left(\log \left(y_{t}\right), \log \left(x_{t}\right), \log \left(l_{t}\right), \log \left(g_{t}\right)\right)^{\prime}$ is the vector of observable variables; $\Gamma_{1}, D$ and $\Psi$ are matrices whose entries are functions of the model structural parameters. The parameters of the VAR process (9) are then estimated by maximizing the likelihood function obtained by using the Kalman filter with the state-space representation (10)-(11). Before performing these calculations, we adjust the data in order to make them consistent with the model, and we remove a deterministic trend of $0.38 \%$ from output, investment and government consumption. ${ }^{11}$

Once we get estimates, the stochastic process used to form expectations about the future is known, and all the wedges, including the investment wedge, can be measured. By construction, when all the wedges are introduced simultaneously, the model will exactly reproduce the observed fluctuations in actual data. Therefore, to assess the relative importance of each wedge for the overall economy, the wedges are fed into the model separately and in combination. For instance, to measure the effect of the labor wedge, the model is simulated by allowing for this wage to vary while the other wedges are fixed to their initial values. This approach allows us to identify which of the four wedges provide the best explanation of the observed economic fluctuations in Italy during the 1982-2008 period.

As far the economic interpretation of wedges is concerned, it is important to bear in mind that the model cannot identify the precise nature of a wedge. As a matter of fact, CMK (2007) show that different models including different types of frictions would produce the same first-order condition as the prototype model we use. Particularly, the labor and investment wedges should not be interpreted only as taxes. On the other hand, the presence of credit restrictions or taxes on consumption or capital income would have similar effects on the investment wedge, with the consequence that introducing a consumption tax into the model would produce the same effect on the investment wedge. Therefore, the latter should be thought of as capturing frictions on investment spending relative to consumption. Moreover, the efficiency wedge captures the level of total factor productivity (TFP) as well as input financing frictions. In short, some caution is necessary when interpreting results concerning the wedges.

\section{Accounting and simulation results}

In this section, we describe the results of applying the BCA to the Italian economy. In reporting our findings, we remove the growth rate of GDP, $\gamma$, to output, investment and government consumption expenditures. Figures, including the measured wedges, are normalized to be 1 in the base period: 1982.1 .

The Italian aggregate data for GDP, investment and hours worked used in our analysis are shown in figure 2. ${ }^{12}$ As can be seen from the figure, after the 1982 recession, output grew by more than trend growth throughout the ' $80 \mathrm{~s}$, with an average annual rate of $2.4 \%$. By the second quarter of 1990, de-trended output was about 7\% above its 1982 level. In the next two decades, however, the growth slowed down, and by the first quarter of 2008, output

\footnotetext{
${ }^{11}$ Consistently with the balanced growth path equilibrium implied by our model, the trend is assumed to be equal to the calibrated quarterly growth rate of technology $\gamma$.

${ }^{12}$ All variables are expressed in per capita values.
} 

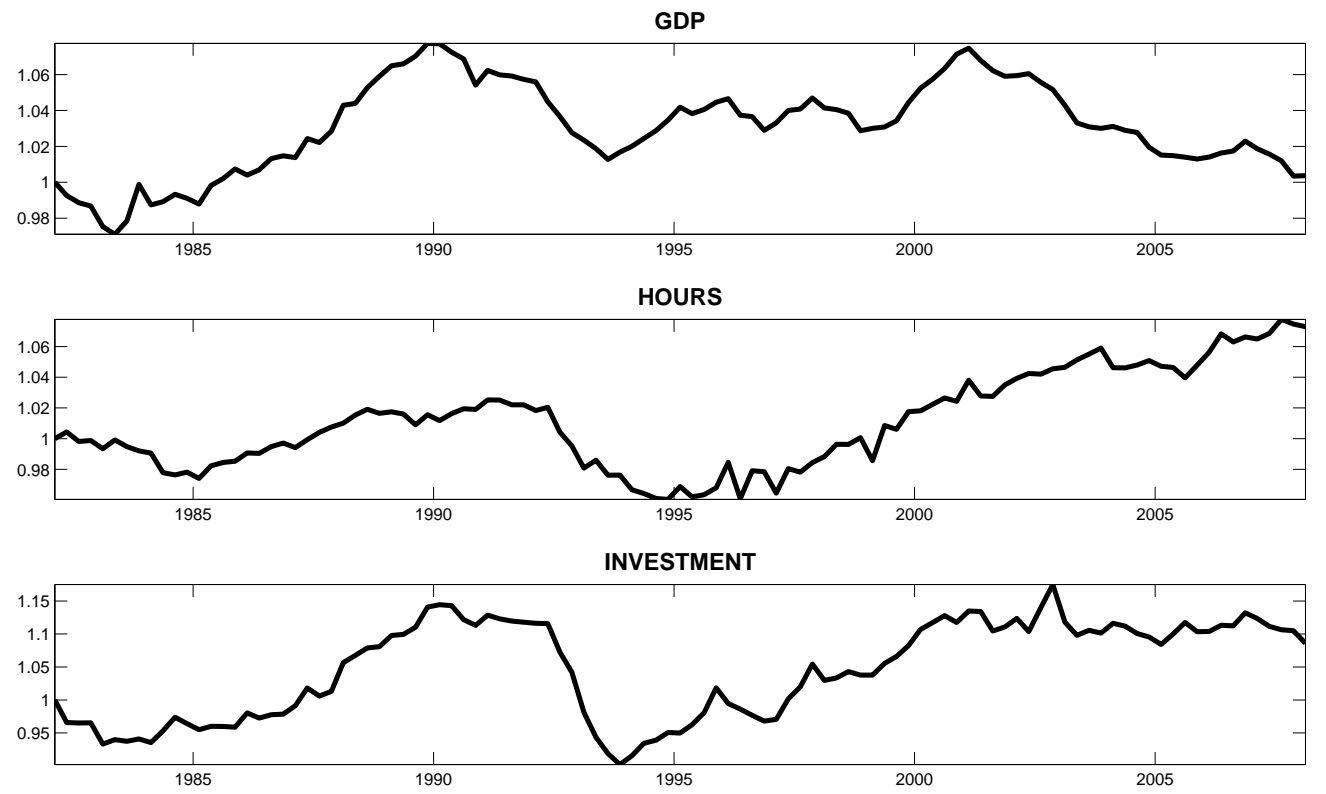

Figure 2: Actual data for GDP, Hours Worked, and Investment. Quarterly data. All the figures with the exception of hours worked are linearly detrended using the rate of technology growth $\gamma$.

was the same as it had been at in 1982. During the last two decades, the rate of growth of output was, on average, substantially below the trend growth, being equal to $1.15 \%$. Per capita investment and hours worked display a very similar pattern. They moved in step with output up to 1995, and then they both consistently increased. By 2008, investment and hours worked are, respectively, 10\% and 7\% above their 1982 levels.

We next analyze the behavior of the four measured wedges. To this end, in figure 3 , we display the four wedges along with actual figures for the Italian output, while in table 2, for HP-filtered data, we report the standard deviations of wedges relative to the output (panel A) as well as the correlations of the wedges with each other and with the output (panel B). These statistics are intended to summarize the salient properties of the wedges at business cycle frequencies. Overall, figure 3 shows that the underlying distortions revealed by the four measured wedges display substantially different behaviors. First, the efficiency wedge, $A_{t}$, positively comoves with output over the entire period of time under consideration. As shown in panel A of table 2, this wedge appears to be strongly and positively correlated with output both contemporaneously (0.86) at various lags and leads. After 1997, however, the efficiency wedge starts to decline much faster than output. As a result, by 2008, the efficiency wedge is in $10 \%$ below its 1982 level, while output was roughly at the same level. Therefore, relative to the previous period, distortions that manifest themselves as an efficiency wedge are substantially worse between 1997-2008. Second, the labor wedge, $\left(1-\tau_{l}\right)$, after increasing early in the sample, drops sharply and then recovers completely so that at the end of the period, it is about 10 percent above the trend. The strong, increasing pattern we observe in the labor wedge between 1997 and 2008 does not square 

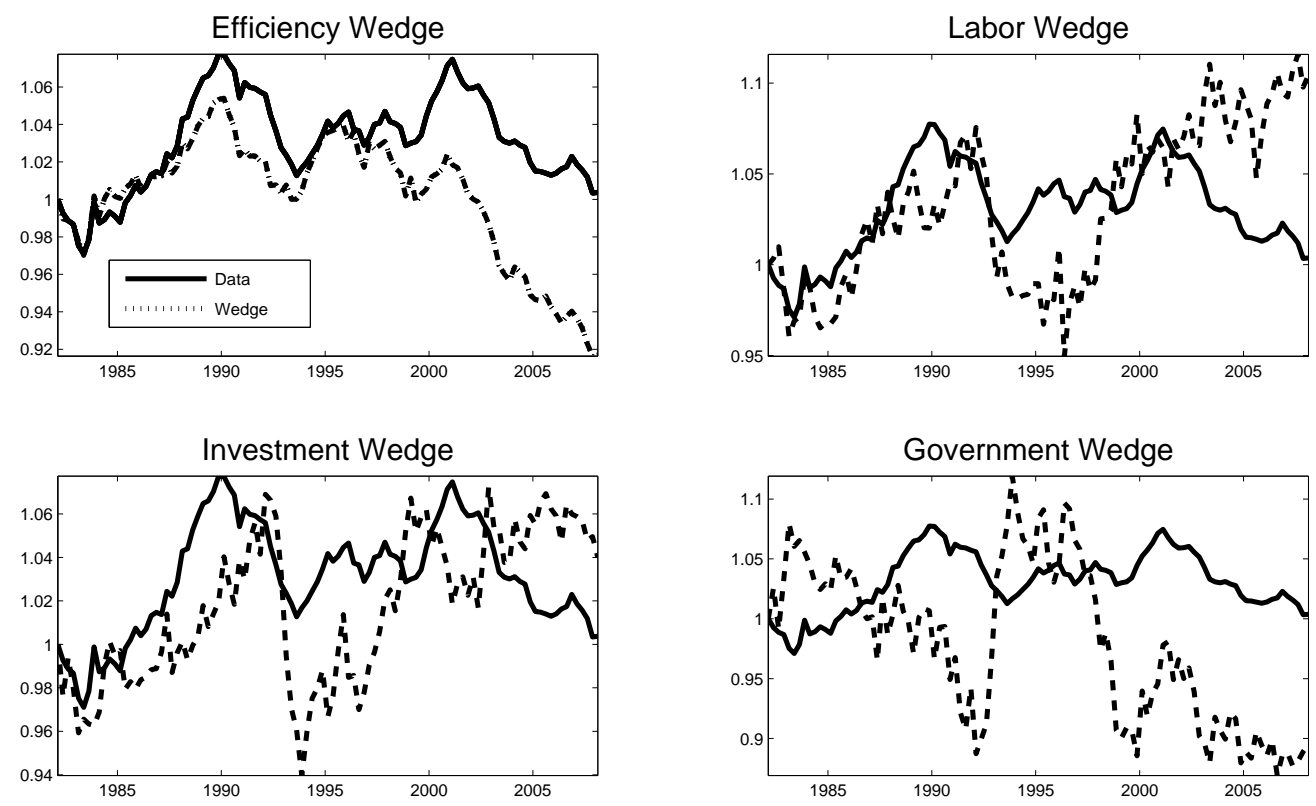

Figure 3: Italian output and measured wedges. The picture shows Italian GDP along with efficiency wedge (panel 1), labor wedge (panel 2), investment wedge (panel 3) and government consumption wedge (panel 4). Data and measured wedges are quarterly and normalized to be 1 in 1982.1.

with output dynamics (the contemporaneous correlation is 0.18 ) and, in particular, shows that labor decisions are relatively less distorted in this period than they are in the previous one. Similarly, the investment wedge, $1 /\left(1+\tau_{x, t}\right)$, moves roughly in step with output until 2002, but after this period, it improves substantially. However, although they display a very similar pattern, ${ }^{13}$ movements in labor wedge are quantitatively more important than movements in the investment wedge, even though the latter is more volatile than the former. Fourth, the government consumption wedge, $g_{t}$, fluctuates around the trend until 1990 and, after a fall in the two subsequent years, has a period of strong recovery between 1992 and 1998 before dropping sharply in the last part of the sample. Table 2 indicates, however, that over the 1982-2008 period, this wedge is essentially uncorrelated with actual output. To conclude, we note that, while the efficiency wedge fluctuates as much as output in the data, the labor, investment and government wedges are much more volatile than actual output, as reported in table 2 .

In order to disentangle the contribution of each wedge to explain the observed dynamics of output, labor, and investment, we next perform several counterfactual experiments. For each wedge, we will first evaluate its marginal effect on those endogenous variables by simulating the model under the assumption that only one wedge fluctuates while the others are kept fixed to their initial values. The estimated figures for output, labor and investment are then compared with the actual data. Additionally, the model's predictions are also

\footnotetext{
${ }^{13}$ The contemporaneous cross-correlation between the investment and labor wedge is 0.51
} 


\section{Output}

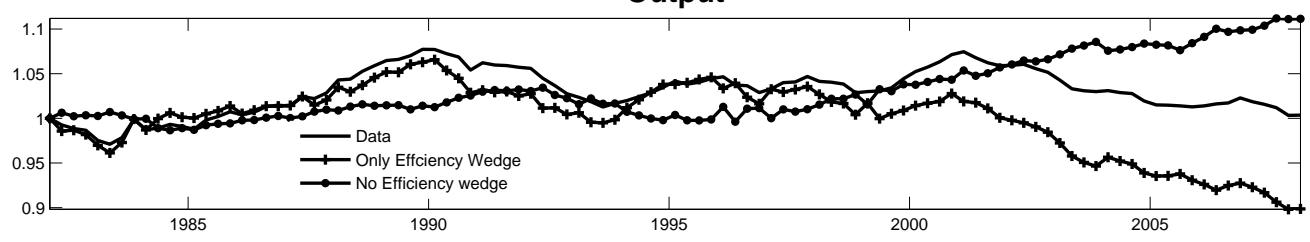

Labor

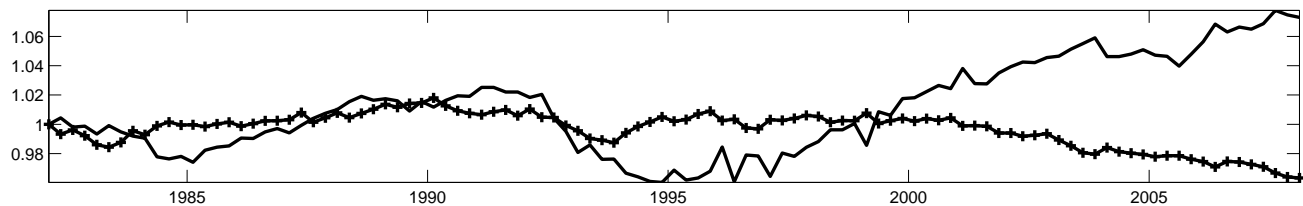

Investment

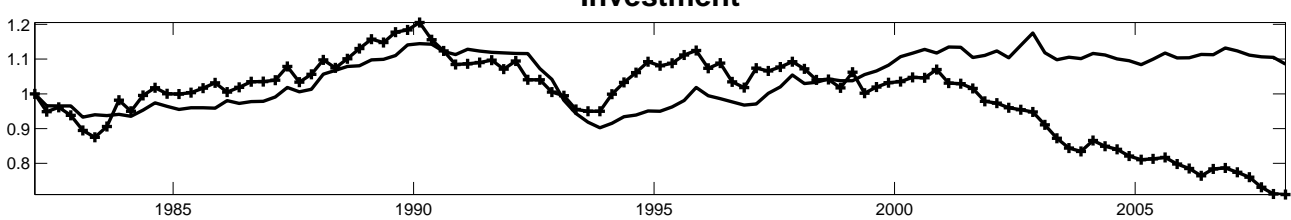

Figure 4: Data and predictions of the models with efficiency wedge. Predictions of the model with efficiency wedge in isolation are labeled only efficiency wedge, while predictions of the model with all but efficiency wedge are labeled no efficiency wedge.

compared with the corresponding figures obtained by the model, using simulations in which we keep fixed one wedge while we allow for all the other wedges to fluctuate. The results are shown in figures 4-7. Moreover, in table 2, for HP-filtered data, we report standard deviations (panel C) as well as the cross correlations (panel D) of output due to each wedge (output components). These statistics summarize the contribution of each wedge to output fluctuations.

Let us first consider the contribution of the efficiency wedge. As shown in figure 4, the efficiency wedge appears to be the main driving force of output during the period between 1982-1997. As a matter of fact, using this wedge alone, predicted output (see the first top panel) completely captures fluctuations of data up to 1997. In this period, the model with the efficiency wedge also does a good job in capturing the slow growth of labor input and the increasing dynamics of investment. In the subsequent period, however, relative to the actual data, the model predicts a much stronger slowdown in output growth. For example, by 2008 , the predicted output falls by about $10 \%$, while the actual Italian output was roughly at the same level that it had been at in 1982. On a yearly basis, the average predicted output growth for the period between 1997-2008 is equal to $0.43 \%$, while in the data, it was equal to $1.3 \%$. The reason for this result is that, during this period, the efficiency wedge accounts for only a small part of the observed fluctuations in both per capita hours worked and per capita investment. In fact, from 1997 to 2008, the model predicts a strong decline in those variables, when they were actually increasing. As such, given the assumed production function (7), the negative effect on output, implied by the decreasing behavior of the measured efficiency wedge, is amplified by the predicted dynamics of both capital 

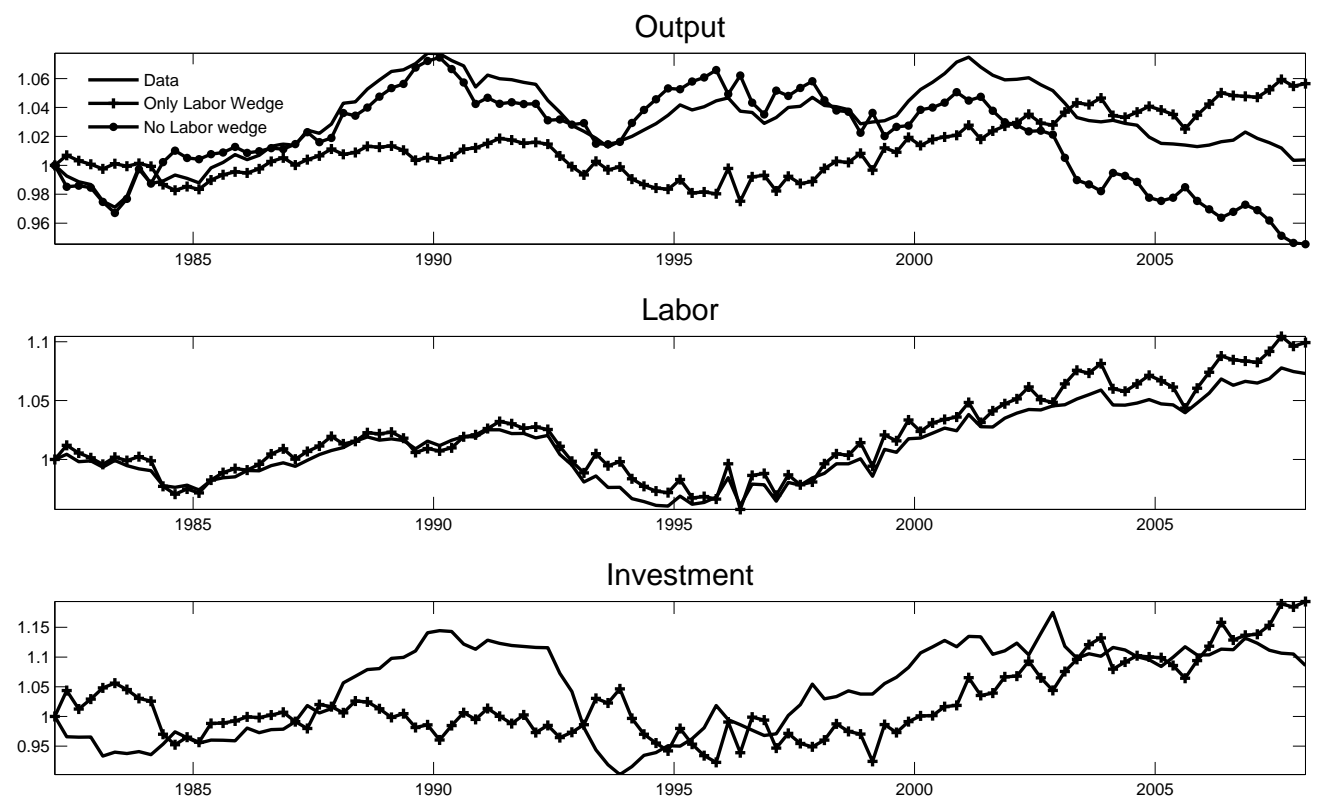

Figure 5: Data and predictions of the models with labor wedge. Predictions of the model with labor wedge in isolation are labeled only labor wedge, while predictions of the model without the labor wedge are labeled no labor wedge.

and labor. The decline in output per capita during 1997-2008 is thus predicted to be much stronger than it actually was in the data.

Note, however, that when this wedge is fixed to its initial value and we allow the other wedge to vary, the model's predictions significantly worsen relative to the case with only the efficiency wedge. In particular, we note that in the period between 1997-2008, output is predicted to constantly increase so that at the end of the period, it is $11 \%$ above its 1982 level; in contrast, the data only show a level that is $0.37 \%$ above its base level (see the dotted line in the first panel of figure 4). Therefore, the downward pressures upon per capita output provided by movements in the efficiency wedge turn out to be crucial to capture the output growth slowdown that characterized this period. As such, distortions that manifest themselves as the efficiency wedge are an important driving force for the Italian fluctuations not only between 1982-1997 but also for the subsequent period between 1997-2008. This result is also confirmed by noting that the output component due to the efficiency wedge is strongly and positively correlated with actual output, both contemporaneously and at various lags and leads (see table 1, panel C). As we will see shortly, the main point of difference is that while in the former subperiod, movements in the efficiency wedge account for almost all fluctuations in the Italian output, during 1997-2008, the output dynamics are explained by a combined contribution from efficiency and labor wedges.

Figure 5 reports the results based on the model with the labor wedge in isolation. Two main features are worth emphasizing. First, movements in the labor wedge capture the observed fluctuations in the per capita hours worked remarkably well. We note in particular that, unlike the efficiency wedge, the labor wedge in isolation succeeds in accounting for the 

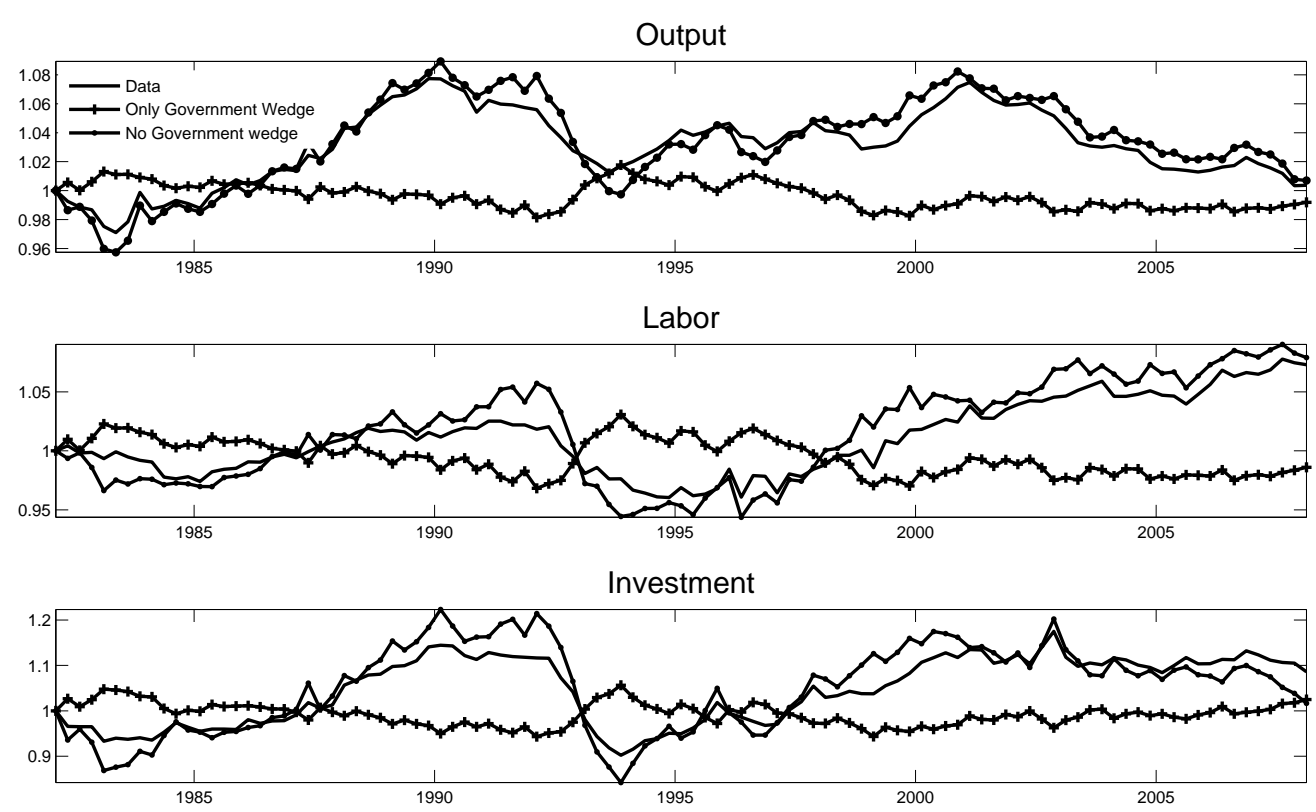

Figure 6: Data and predictions of the models with government wedge. Predictions of the model with government wedge in isolation are labeled only government wedge, while predictions of the model without the government wedge are labeled no government wedge.

constant increase in per capita hours worked that occurred in Italy since 1997. In this case, the result is driven by the effect of the labor wedge on the supply of hours. As a matter of fact, an increase in the labor wedge, $\left(1-\tau_{l, t}\right)$, such as the one we observe in figure 3 from 1997 to 2008, shifts the labor supply to the right by affecting the consumer's intratemporal condition (3), thereby providing upward pressure on the equilibrium level of hours worked, which eventually increases. Moreover, because of consumption smoothing, the higher labor income experienced by consumers also leads to an increase in the equilibrium level of investment. This mechanism explains why in the model with only the labor wedge, predicted investment also increases during the period 1997-2008, thereby capturing the actual pattern.

Second, predictions based on the model with only the labor wedge generally miss the observed output dynamics; in sharp contrast with the actual data, the labor wedge in isolation predicts output to grow along the trend up to 1997 and increase steadily thereafter. As a matter of fact, we find that the correlation between output components due to the labor wedge and actual output is positive but small (0.16), as reported in panel C of table 2 . Note, in particular, that for the period 1997-2008, the model does a good job in accounting for the strong recovery of both labor and investment but that the predicted output growth is completely at odds with the data. The reason for this discrepancy is that by keeping the efficiency wedge fixed to its 1982 value, the model with only the labor wedge does not account for a potential decline in TFP, which, as we mentioned earlier, seems to be a potential explanation for the slowdown in the Italian per capita output growth that occurred during that period. 


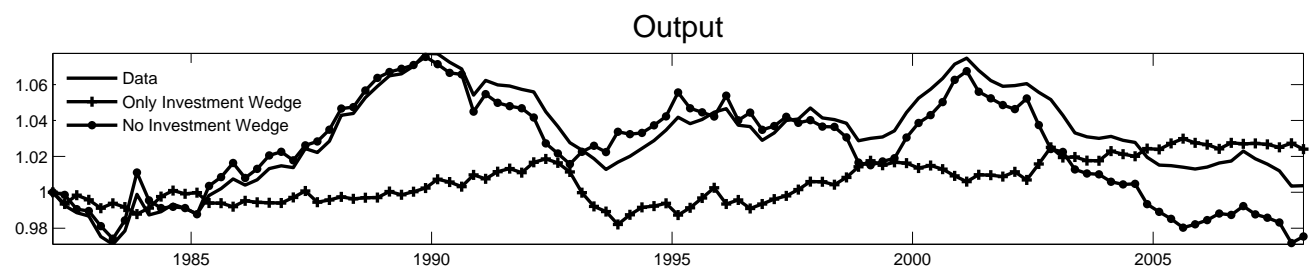

Labor

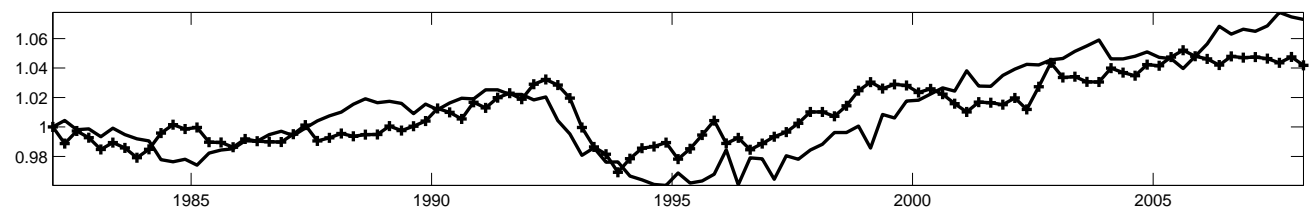

Investment

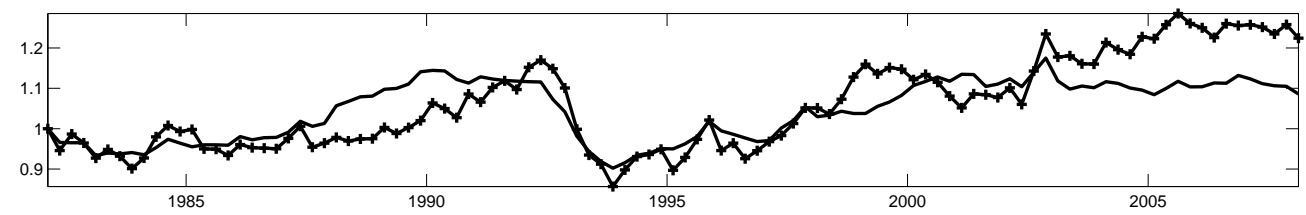

Figure 7: Data and predictions of the models with just investment wedge. Predictions of the model with investment wedge in isolation are labeled only investment wedge, while predictions of the model without the investment wedge are labeled no investment wedge.

Nevertheless, relative to the case with only the efficiency wedge (see figure 4), we notice that keeping the labor wedge constant while allowing for all the other wedges to vary does not improve the model's predictions for the period between 1997-2008. In fact, as can be seen from figure 5, the model without the labor wedge predicts a slowdown in the per capita output growth (on average, $0.72 \%$ ) that is still substantially more severe than what occurred. This result suggests that in this period, the measured improvement in the labor wedge, possibly through its effect on per capita hours worked, partially offsets the decline in the efficiency wedge and may have contributed to the observed fluctuations of the per capita output, particularly in preventing an even stronger decline. This result is consistent with the fact that output components due to the efficiency and labor wedges are contemporaneously negatively correlated $(-0.29)$. We will return to this point shortly.

In figure 6, we display the separate contribution of the government wedge. We see that this wedge completely misses the observed dynamics in all the three variables we have considered. Moreover, when the model is simulated by keeping only this wedge constant, we note that the predictions notably improve, replicating the observed fluctuations in all three variables substantially well. Therefore, we can reasonably assume that this wedge is not responsible for the stagnation phase that has characterized the Italian economy during the considered period of time. This finding is not surprising, as this wedge appears to be essentially uncorrelated with output (see table 2). Note also that this property holds true 
even when we consider the output components. ${ }^{14}$

We next consider the investment wedge. As shown in figure 7, the results based on the model with the investment wedge are quite similar to those obtained in the case of the model with the labor wedge. While capturing the observed dynamics in both per capita investment and per capita hours worked sufficiently well, the predicted output generally misses the actual dynamics. For instance, in the period between 2000-2008, output is predicted to grow slightly more than the trend growth while in the data, it declined substantially. As for the labor wedge, keeping the investment wedge fixed substantially improves the model's predictions. There is, however, a remarkable difference between the investment and the labor wedges. Relative to the case with the fixed labor wedge, we note that when we keep the investment wedge fixed while allowing all the other wedges to vary, the predictions of the model also improve in the 1997-2008 period. In fact, while the model still predicts a stronger slowdown, we see that the predicted output is closer to the data. In this case, the predicted average growth rate of the output is equal to $1 \%$ and thus much closer to what we observe in the data. Overall, this result suggests that frictions captured by movements in the investment wedge have played a relatively minor role in accounting for fluctuations in the Italian output during the period under consideration.

To conclude, we next analyze output predictions generated by models in which we allow for two wedges to contemporaneously vary. Our main goal is to identity distortions that generate output predictions that are as close as possible to the actual data. In particular, our analysis focuses on the combined contribution from efficiency and labor wedges, or alternatively, from the combination of efficiency and investment wedges. On the one hand, we left out the government wedge, as we have shown that its contribution to output fluctuations is insignificant. On the other hand, we have shown that, although the efficiency wedge appears as the main driving force behind the observed fluctuations, in the period between 1997-2008, the model with only the efficiency wedge predicts a slowdown in output growth that is much larger than what we observe in the data. This suggests that during this period, the negative effects upon the per capita output of movements of the efficiency wedge are partially offset by countervailing effects provided by other wedges. The analysis we have provided so far tends to identify those factors as the labor and investment wedges.

Figure 8 displays the results by drawing the model's predictions along with actual observations of the per capita output. As shown in the figure, our experiments show that essentially all of the fluctuations in Italian output are accounted for by movements in efficiency and the labor wedge. Focusing on the period between 1997-2008 and leaving out the investment and government wedges results in predictions that are much closer to the observed data. In fact, in this period of time, the model with efficiency and labor wedges predicts an average output growth of $1.1 \%$, in line with what we observe in the data. As mentioned before, this result suggests that during the period between 1997-2008, the measured improvement in the labor wedge, through its effect on the equilibrium level of hours worked, may have partially offset the negative impact on the per capita output of the declining pattern of the efficiency wedge. As a result, the model with those two wedges captures the actual fluctuations in the per capita output remarkably well. Conversely, leaving aside labor and government wedges results in predictions that are generally more volatile than

\footnotetext{
${ }^{14}$ In this case, however, the correlation is negative.
} 


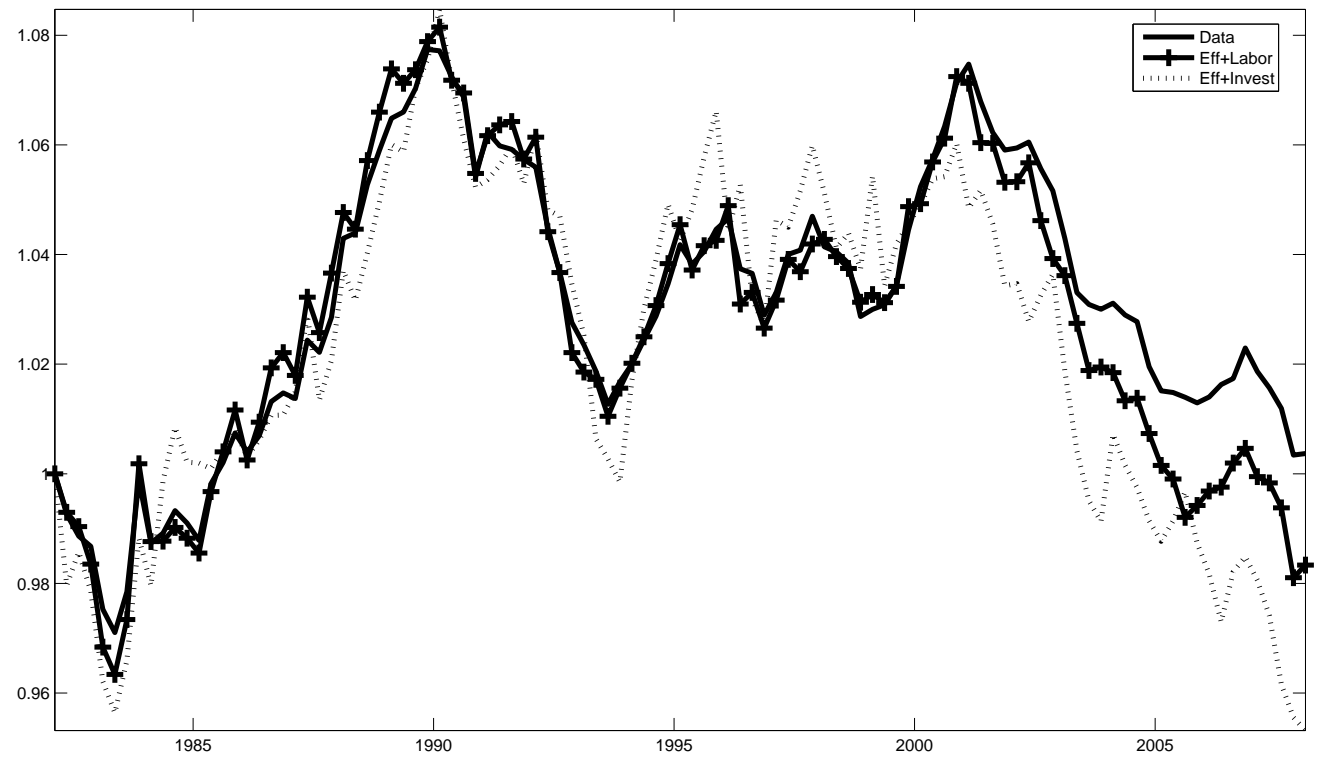

Figure 8: Data and predictions of the models with combination of wedges.

the actual data. Moreover, for the period between 1997-2008, the predicted output drop is much larger than what we observed in the actual data. This finding confirms that, if there is any effect, the investment wedge has played a relatively minor role in accounting for fluctuations in Italian output.

In summary, our analysis shows that the observed fluctuations in Italian output in the 1982-2008 period are mainly driven by distortions that manifest themselves as efficiency and labor wedges. Detailed models on the Italian economy should therefore take into account those two type of frictions. As far as the Italian stagnation phase is concerned, we find that, over the last 15 years, the slowdown in the Italian per capita growth rate is essentially driven by a substantial worsening in the distortions captured by the efficiency wedge. Models based on the other wedges in isolation all fail to capture the downturn in per capita output that occurred in the 2000s. This result is clearly consistent with the findings of Daveri and JonaLasinio (2005), which show that the poor economic performance of the Italian economy can be ascribed to a decline in TFP in general and to a decline in labor productivity in particular. Our analysis, however, provides additional insights to the existing literature, showing that the improvement in the labor market distortions, as they are captured by the labor wedge, is important to understanding labor dynamics in Italy, particularly for the last 15 years. In addition, and most importantly, we found that, during the stagnation phase, the increasing improvement in the labor wedge has partially offset the negative impact of the decline in the efficiency wedge, preventing an even stronger decline in the per capita GDP growth. Relative to the actual data, the model with the efficiency wedge alone predicts a much stronger decline in output per capita. 
Table 2: Properties of the Wedges and Output Components

\begin{tabular}{|c|c|c|c|c|c|c|}
\hline \multicolumn{7}{|l|}{ "A. Summary Statistics } \\
\hline \multirow[b]{2}{*}{ Wedges } & \multirow{2}{*}{$\begin{array}{c}\text { Standard Deviation } \\
\text { Relative to GDP }\end{array}$} & \multicolumn{5}{|c|}{ Correlation of wedges with GDP at lag $\mathrm{K}=$} \\
\hline & & -2 & -1 & 0 & 1 & 2 \\
\hline Efficiency & 0.95 & 0.62 & 0.78 & 0.86 & 0.67 & 0.46 \\
\hline Labor & 1.67 & 0.04 & 0.09 & 0.18 & 0.16 & 0.14 \\
\hline Investment & 1.81 & -0.08 & 0.06 & 0.14 & 0.18 & 0.23 \\
\hline Govt. Cons. & 3.44 & 0.16 & 0.07 & 0.01 & -0.03 & -0.08 \\
\hline \multicolumn{7}{|l|}{ B. Cross Correlations } \\
\hline & & \multicolumn{5}{|c|}{ Correlation of $\mathrm{X}$ with $\mathrm{Y}$ at lag $\mathrm{K}=$} \\
\hline $\operatorname{Wedges}(X, Y)$ & & -2 & -1 & 0 & 1 & 2 \\
\hline Efficiency, labor & & -0.09 & -0.09 & -0.19 & -0.18 & -0.20 \\
\hline Efficiency, investment & & 0.08 & 0.01 & -0.01 & -0.16 & -0.31 \\
\hline Efficiency, government & & 0.09 & 0.18 & 0.23 & 0.31 & 0.38 \\
\hline Labor, investment & & 0.39 & 0.46 & 0.51 & 0.45 & 0.37 \\
\hline Labor, government & & -0.42 & -0.54 & -0.78 & -0.53 & -0.40 \\
\hline Investment, government & & -0.51 & -0.69 & -0.91 & -0.69 & -0.49 \\
\hline \multicolumn{7}{|l|}{ C. Summary Statistics } \\
\hline & Standard Deviation & \multicolumn{5}{|c|}{ Correlation of wedges with GDP at lag $\mathrm{K}=$} \\
\hline Output Components & Relative to GDP & -2 & -1 & 0 & 1 & 2 \\
\hline Efficiency & 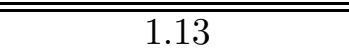 & 0.61 & 0.78 & 0.87 & 0.68 & 0.48 \\
\hline Labor & 0.60 & 0.11 & 0.09 & 0.16 & 0.18 & 0.16 \\
\hline Investment & 0.52 & -0.18 & -0.05 & 0.02 & 0.11 & 0.19 \\
\hline Govt. Cons. & 0.50 & 0.08 & -0.04 & -0.12 & -0.14 & -0.17 \\
\hline \multicolumn{7}{|l|}{ D. Cross Correlations } \\
\hline & & \multicolumn{5}{|c|}{ Correlation of $\mathrm{X}$ with $\mathrm{Y}$ at lag $\mathrm{K}=$} \\
\hline Output Components $(X, Y)$ & & -2 & -1 & 0 & 1 & 2 \\
\hline Efficiency, labor & & -0.07 & -0.08 & -0.29 & -0.17 & -0.12 \\
\hline Efficiency, investment & & 0.10 & 0.01 & -0.01 & -0.19 & -0.35 \\
\hline Efficiency, government & & -0.08 & -0.04 & -0.07 & 0.10 & 0.25 \\
\hline Labor, investment & & 0.22 & 0.18 & 0.03 & 0.21 & 0.27 \\
\hline Labor, government & & -0.23 & -0.23 & -0.21 & -0.25 & -0.26 \\
\hline Investment, government & & -0.46 & -0.68 & -0.93 & -0.73 & -0.55 \\
\hline
\end{tabular}

Note: Series are first logged and detrended using the HP filter.

\section{The labor wedge and labor market reforms in Italy}

In this section, we try to identify which types of distortions are captured by the measured labor wedge, particularly focusing on the period between 1997-2008. First, we want to ascertain whether the labor wedge captures movements in the effective marginal tax rate in Italy. This is a natural starting point for our analysis, as the labor wedge in the prototype economy precisely resembles taxes on the labor income. To this end, as in Ahearne, Kydland and Wynne (2006), we apply the methodology proposed by Martinez-Mongay (2000) to construct data for the effective tax rate on labor income in Italy for the period between 
1982-2008. More precisely, by using annual data, we first obtain figures for the effective tax rate on labor income, $\tau_{L, t}$, and the effective tax rate on consumption, $\tau_{C, t}$, and then, following Prescott (2004), we recover figures for the tax wedge, which is given by the formula

$$
\hat{\tau}_{t}=\frac{\tau_{C, t}+\tau_{L, t}}{1+\tau_{C, t}}
$$

These data for the effective tax wedge are then compared with the yearly average of the measured labor wedge. ${ }^{15}$ Panel 1 of figure 9 plots such a comparison, and, as can be seen from the figure, the two series appear to be negatively correlated (-0.45), generally moving in the opposite direction. While the labor wedge fluctuated over the whole sample, the effective tax rate on labor income instead shows a clear upward trend. If we restrict our attention to the relevant period, 1997-2008, we see that the two series tend to diverge and are only slightly positively correlated (0.16). Therefore, this result suggests that the improvement in the distortions captured by the measured labor wedge for this period of time is only minimally explained by movements in the effective tax rates, meaning that other factors have contributed mostly in reducing the distortions in the labor market.

In order to learn more about the driving forces behind the increase in the total amount of hours worked that occurred in Italy during the period between 1997-2008, we next decompose the per capita hours worked into extensive (employment over population) and intensive margins (hours per employees). This result allows us to disentangle the marginal effect of those two margins on hours worked, thereby understating which of them is mainly responsible for the observed labor dynamics. Results are provided in panels 3 and 4 of figure 9, where the intensive and extensive margins are plotted along with the actual hours worked. The figure clearly shows that the steady increase in the per capita hours worked we observe in the period 1997-2008 is mainly driven by the extensive margin. While, in fact, the hours per employees essentially decline over the whole sample (panel 3), we note that the ratio of employment to population (panel 4) has instead moved in step with per capita hours, dramatically increasing from 1997 to 2008. As a matter of fact, during this period of time, Italy has experienced an important acceleration in employment growth. According to the OECD data- LFS database- from 1997 to 2008, the employment growth in Italy was, on average, equal to $1.25 \%$ each year. This is a huge improvement in comparison with the period between 1982-1996, where the employment growth rate was, on average, equal to $-0.11 \%$.

The literature agrees that such an acceleration of employment growth is mainly due to a sequence of labor market reforms that has characterized the Italian economy in the last 15 years (Boeri and Garibaldi, 2007). As for the rest of Europe, during the '90s, Italy was characterized by important labor market policies that were primarily oriented at increasing the flexibility of the labor factor, ultimately making the utilization of nonpermanent labor contracts more loosely regulated. In particular, these reforms aimed at the elimination of most restrictions on the use of non-causal fixed-term contracts, which are characterized by much lower firing costs than those of permanent (open-ended) contracts. This process began in 1987 with the deregulation of fixed-terms contracts (act 56/1987). Since then, temporary contracts have been allowed through collective agreements and prior

\footnotetext{
${ }^{15}$ We take the yearly average, as data for effective tax rates are available only at yearly frequencies.
} 

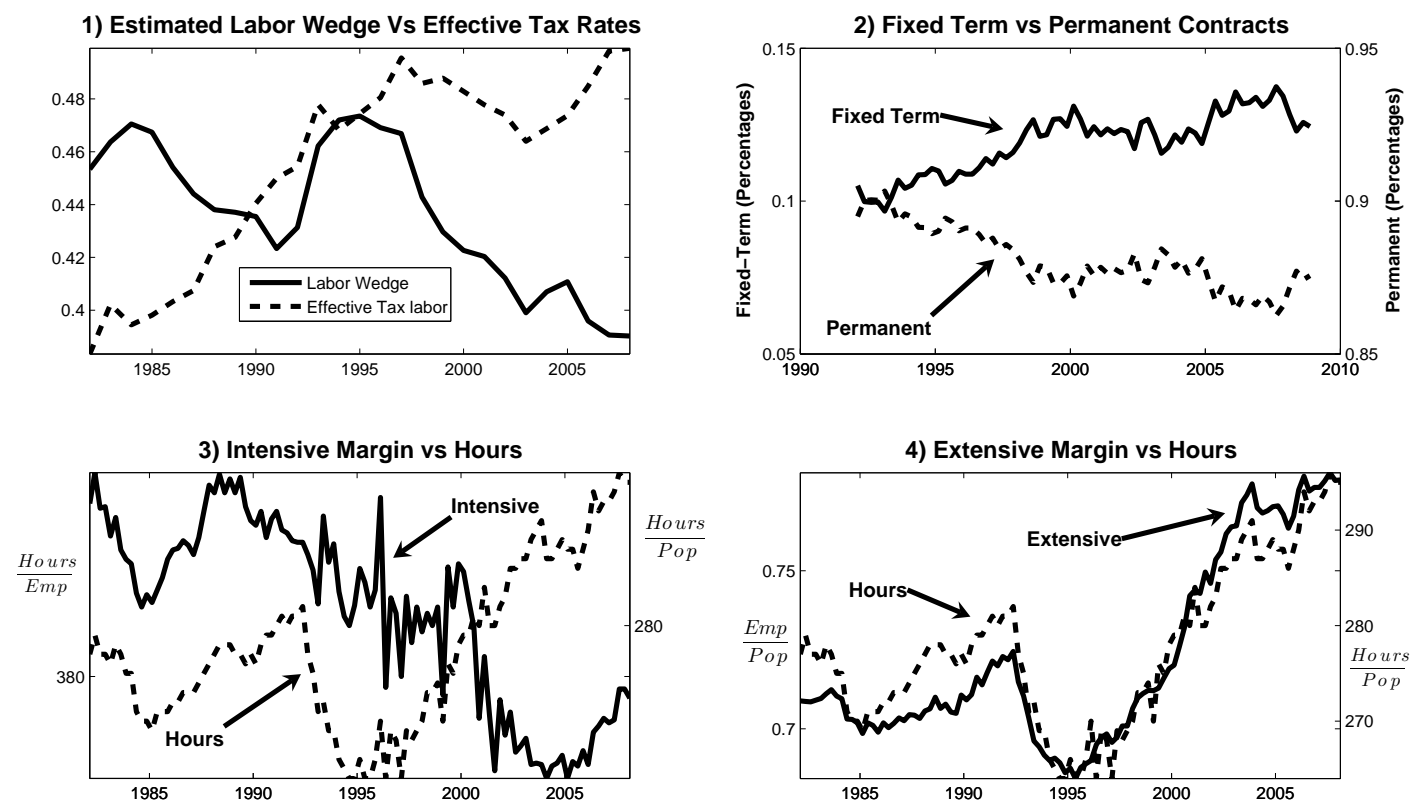

Figure 9: The labor wedge and labor market reforms in Italy. Panel 1 compares the measured labor wedge with the marginal tax rate on labor income. Panel 2 graphed total employees with fixed-term contracts (right scale) and total employees with permanent contracts as fractions of total employment. Total employment refers to dependent employees. Panel 3 compares the intensive margin (right scale) with per capita hours worked (left scale). Panel 4 compares the extensive margins (right scale) with per capita hours worked (left scale).

administrative authorizations. The most important reform, however, took place in 1997 (the so-called Treu law, act 196/1997), which, among other acts, legalized the hiring of temporary workers through authorized agencies to the advantage for the employers by reducing social security contributions and pension provisions, similarly encouraging atypical labor contracts. This law was given an extension in 2003 (the so-called Biagi law, act 30/2003), which introduced new types of temporary work contracts, such as job-on-call, job sharing and supplementary work.

Available aggregate data suggests that these reforms have significantly affected the Italian labor market. First, as it appears from panel 2 of figure 9, the share of temporary contracts over total dependent employment has constantly increased over the last two decades, accounting in the year 2008 for almost $14 \%$ of total dependent employment. This entails that after the 1997 reform, the contribution of temporary jobs to aggregate employment growth in the Italian economy became significant (see Boeri and Garibaldi, 2007). Second, according to the results provided by Cipollone and Guelfi (2006), as a consequences of these institutional reforms, during 1995-2003 the share of fixed-term contracts among new hires grew from 34 to 42 per cent, and, in particular their estimates, based on a panel of Italian industries, indicate that the labor cost reduction associated with this expansion amounted 
to about 17 per cent. The authors conclude that the advent of flexibility in the Italian labor market can account for a large share of employment growth in the private sector. Finally, according to the OECD data, the employment protection legislation (EPL) index in Italy has constantly decreased after the 1997 reform, moving from 3.57 in the 1985 to 1.89 in the 2008. This pattern is entirely driven by the decline in the EPL index for temporary employment as the EPL indexes for both permanent jobs (regular employment) and collective dismissals remain unchanged from 1985 to 2008.

These main features of the Italian labor market are clearly consistent with our findings related to the labor wedge. From 1997 to 2008, the measured labor wedge displays a strongly increasing pattern that squares with both hours worked and employment dynamics in Italy. This trend in the labor wedge should capture the improvement in labor market distortions, due to the decline of the firms' firing costs associated with the increased flexibility as well as the reduction in search costs for both firms and job seekers due to the legalization of temporary work agencies. From this perspective, our analysis also contributes to the literature evaluating the effect of labor market reforms. We have shown that for understanding labor dynamics in Italy in the last 15 years, it is crucial to take into account distortions that manifest themselves as a labor wedge. The potential connection between a labor wedge and labor market reforms can then be interpreted as an another piece of evidence showing the impact of such reforms in the Italian labor market.

\section{Concluding Remarks}

In this paper, we analyzed the decline of the Italian economy by using a business cycle procedure following the methodology outlined in Chari, Kehoe and McGrattan (2007). Our findings suggest that the efficiency wedge was the most important source of output fluctuations during the considered period and that was revealed to be the main driving force behind the stagnation phase characterizing the Italian economy in the last 15 years. Nevertheless, in second part of the sample, which began near 1997, improvements in the labor wedge were revealed to be essential in explaining labor market dynamics. Our analysis suggests that such improvements are mainly related to important labor market reforms that took place in Italy since the second half of the '90s. In addition, our findings suggest that improvements in the labor wedge partially offset the negative impact of the efficiency wedge, preventing

an even stronger slowdown in per capita output growth. Our results are consistent with the existing literature and provide some additional insights for understanding the poor performance of the Italian economy, showing the prominent role of the labor wedge in the last 15 years. Detailed DSGE models on the Italian economy for this period of time should take into account frictions that manifest themselves as efficiency and labor wedges. 


\section{References}

[1] Ahearne, A.,F. Kydland, and M. A. Wynne, (2006). "Ireland's Great Depression," The Economic and Social Review, Economic and Social Studies, vol. 37(2), pages 215-243.

[2] Arpaia, A., Perez, E. and Pichelmann, Karl, (2009), "Understanding labour income share dynamics in Europe," MPRA Paper (15649), University Library of Munich, Germany.

[3] Blanchard O. (2004). "The Economic Future of Europe," NBER Working Papers 10310, National Bureau of Economic Research, Inc.

[4] Boeri, T. and P. Garibaldi, (2007), "Two Tier Reforms of Employment Protection: a Honeymoon Effect?," Economic Journal, Royal Economic Society, vol. 117(521), pages 357-385, 06.

[5] Canova F. (2007), "Methods for Applied Macroeconomic Research," Princeton University Press

[6] Chari,V. V., Patrick J. Kehoe and Ellen R. McGrattan, (2007) "Business Cycle Accounting," Econometrica, Econometric Society, vol. 75(3), pages 781-836, 05.

[7] Cipollone, P. and A. Guelfi, 2006. "The value of flexible contracts; evidence from an italian panel of industrial firms," Temi di discussione (Economic working papers) 583, Bank of Italy, Economic Research Department.

[8] Daveri, F. and C. Jona-Lasinio, 2005. "Italy's Decline: Getting the Facts Right," Giornale degli Economisti, GDE (Giornale degli Economisti e Annali di Economia), Bocconi University, vol. 64(4), pages 365-410, December.

[9] ISTAT, The Italian Statistical Institute: "Productivity Statistics: 1980-2007".

[10] Kersting, E.K. (2008) "The 1980s recession in the UK: A business cycle accounting perspective", Review of Economic Dynamics, vol. 11, pp. 179-191.

[11] Martinez-Mongay, C., 2000. "ECFIN's Effective Tax Rates. Properties and Comparaisons with other Tax Indicators," European Economy - Economic Papers 146, Commission of the EC, Directorate-General for Economic and Financial Affairs (DG ECFIN).

[12] McGrattan, Ellen R. and Edward C. Prescott, (2007) "Unmeasured Investment and the Puzzling US Boom in the 1990s," NBER Working Papers 13499, National Bureau of Economic Research, Inc. 


\section{Data Appendix}

\section{Business Cycle Accounting}

\section{Per Capita Output,}

Per capita output, $y_{t}=($ GDP-Sales taxes $) /$ Woring-age population where

$\mathrm{GDP}=\mathrm{GDP}$ in constant market prices, millions of 2000 euro.

Source: CONISTAT (http://con.istat.it/amerigo/default.asp), series ncfh3.PIL_FF.D

Sales Taxes $=$ VAT + net taxes on products + import taxes, millions of 2000 euro.

Source: CONISTAT databank, series nvbh6.IVA.D

Working-age population $=$ Population aged $15-64$

Source: ISTAT.

\section{Per capita hours worked}

Per capita hours worked, $l_{t}=$ (Total quarterly hours actually worked/Working-age population $) /(47 / 4$ weeks $\times 112$ hours per week) where

Total quarterly hours actually worked= Quarterly seasonally adjusted hours worked from CONISTAT, series nvhbb.TOT.D

\section{Per capita investment}

Per capita investment, $x_{t}=$ (Gross fixed investment + Personal consumption expenditures on durables - Sales Taxes $\times$ Share of consumer durables in total consumer spending) /(Working-age population) where

Gross Fixed Investment= Gross domestic capital formation, millions of 2000 euro

Source: CONISTAT databank, series ncfh3.INVFLTOF.D

Share of consumer durables in total consumer spending $=$ (Consumption of durable goods/Total consumption)

Source: CONISTAT databank, series nci5c.DUR.D (Durables) and nci5c.TOTCFN.D (Total), millions of 2000 euro.

\section{Per capita government consumption}

Per capita government consumption, $g_{t}=$ (Goverment Consumption + Net Exports)/(Workingage population)

where

Government consumption: Government expenditures, millions of 2000 euro

Source: CONISTAT databank, series ncfh3.CONFCOF.D 
Net Export $=$ Net export of goods and services, millions of 2000 euro.

Source: CONISTAT databank, series ncfh3.ESPBS_FF.D (Exp), ncfh3.IMPBS_FF.D $(\operatorname{Imp})$

\section{Figure 1}

Per capita GDP for Spain, Italy, France, Germany and the UK from The Conference Board Total Economy Database. ${ }^{16}$.

\section{Table 1}

\section{GDP Growth}

Source: The Conference Board Total Economy Database.

\section{Employment Growth}

Source: the OECD, LFS database.

\section{Labor productivity growth and components}

Source: $\operatorname{ISTAT}^{17}$

\section{Figure 9}

\section{Effective tax wedge}

Yearly series estimated with the methodology of Martiez-Mongay (2000) using data from AMECO databank. ${ }^{18}$

\section{Intensive and Extensive Margins}

Extensive Margin=(Total Employment/ Working-age population $)$

Intensive Margin $=($ Total Hours Worked/Total Employment $)$ where

Series for Total Employment from CONISTAT databank

\footnotetext{
${ }^{16}$ The Conference Board Total Economy Database, January 2010, http://www.conferenceboard.org/economics/database.cfm

${ }^{17}$ http://www.istat.it/salastampa/comunicati/non_calendario/20081113_00/productivity_statistics.pdf

${ }^{18}$ http://ec.europa.eu/economy_finance/db_indicators/ameco/index_en.htm
} 


\section{Share of temporary workers in total dependent employment}

Source ISTAT http://www.istat.it/lavoro/lavret/forzedilavoro/serie.html.

Note: The series have been seasonally adjusted by using the X11 filter. 


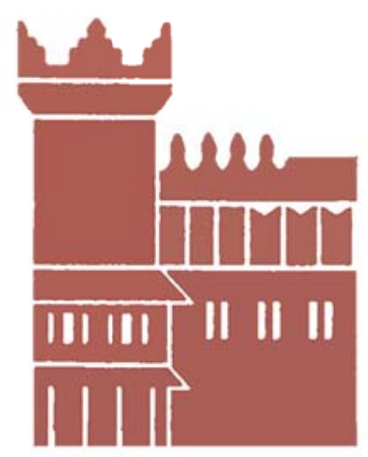

Alma Mater Studiorum - Università di Bologna DEPARTMENT OF ECONOMICS

Strada Maggiore 45

40125 Bologna - Italy

Tel. +39051 2092604

Fax +390512092664

http://www.dse.unibo.it 